\title{
Mekanik Bir Robot Tutucusu Tasarımı ve İmalatı
}

\author{
Savaş KOÇ ${ }^{1 *}$, Cengiz DOĞAN ${ }^{2}$ \\ ${ }^{1}$ Batman Üniversitesi, Mühendislik Fakültesi, Makina Mühendisliği Bölümü, Batman \\ ${ }^{2}$ Harran Üniversitesi, Mühendislik Fakültesi, Makine Mühendisliği Bölümü, Haliliye, Şanlıurfa \\ (ORCID: 0000-0002-5257-3287) (ORCID: 0000-0002-1468-8462)
}

\begin{abstract}
$\ddot{O} z$
Tutucular, robot kol sistemlerinde gerçek iși yapan kısımlardır. Uygulamalarda kullanılan tutucular; hidrolik, pnömatik ve mekanik tahriklidir. Bu çalışmada tasarlanan tutucu mekanik olarak tahrik edilir. Bir tarafta sağ trapez vida ve diğer tarafta sol trapez vida parçalar aynı eksende rulmanların yardımı ile iki parça olarak tasarlanmıştır. Dişliler, kasnak ve zincir kullanılarak birlikte hareket ettirilir. Kasnak zincir hareketlerinde sol ve sağ vidaların açılması ve kapanması yönleri terstir. Zincir bir tarafa çevrildiğinde, dönüşleri engellenen vidalar üzerindeki somunlar içe ve dışa doğru açılır. Tahrik sisteminde ise dik açılı bir matkap motoru kullanılmıştır. Vidalar, mekanik güç kullanılarak hareket ettirilir. Parçayı kavrayan çeneler, somunlara yerleştirilen bir V bloğu şeklinde iki karşıı parçadan oluşur. Motor hareketleri, parçanın alınması ve bırakılması sırasında mekanik sınır anahtarlarıyla kontrol edilir. Motorun parçayı tutması sırasında sıkıştırmayı önlemek için yaylar çenenin bir tarafina yerleştirilmiştir. Dişlilerin döndürülmesiyle tutucu, parçaları tutarak, kaldırarak ve istenen konuma bırakarak çalışır. Bu çalışmada, tasarlanan tutucu kullanılarak silindirik ve prizmatik malzemeler bir yerden alınarak başka bir yere bırakır. Tutucu, parçaların taşınmasına ek olarak ayrıca iki eksende hareket sağlayarak parçanın alma ve bırakma pozisyonlarının artırılmasına da yardımcı olur. Üç eksende hareket eden mafsalı bir robotun uçuna takılmasıyla robotun beş eksende hareket etmesi sağlanmıştır. Beş eksende hareket eden robot endüstride, parçaların bantlar üzerinde taşınması işlemi ve hareketli bantlar üzerinde bulunan parçaları paketleme gibi işlemlerde kullanılarak değerlendirilebilir.
\end{abstract}

Anahtar kelimeler: Tutucu, endüstriyel robot, sağ ve sol vida, açılı matkap.

\section{Design and Manufacture of a Mechanical Robot Gripper}

\begin{abstract}
Grippers are the parts that do the real work in the robot arm systems. Grippers used in applications; hydraulic, pneumatic and mechanically driven. The designed gripper in this study is driven mechanically. A right trapezoidal screw on one side and a left trapezoidal screw parts on the other side are designed in two parts with the help of bearings on the same axis. The gears are moved together by using pulley and chain. In the pulley chain movements, the direction of opening and closing of the left and right screws is inverse. When the chain is turned to one side, the nuts on the gears whose turns are blocked are opened inwards and outwards. A right-angle drill motor is used in the drive system. After the motor is assembled on the system, the retaining jaws are rotatably mounted with chains and pulleys. The jaws that hold the part consist of two opposing pieces in the form of a vee block placed on the nuts. Motor movements are controlled by mechanical limit switches during pickup and release of the part. The springs are placed on one side of the jaws to prevent compression when the motor is holding the part. By rotating the gears, the holder works by holding the parts, lifting them and releasing them to the desired position. In this study, using designed the gripper, cylindrical and prismatic materials are taken from one place to another. In addition to the carriage of the parts, the gripper also provides movement in two axes to help increase the pickand-release positions of the part. It is attached to the end of an articulated robot that moves in three axes, so that the robot moves in five axes. The robot moving in five axes can be evaluated in the industry using processes such as transporting parts on belts and packing parts on moving belts.
\end{abstract}

Keywords: Gripper, industrial robot, right and left screws, angle drill.

*Sorumlu yazar: savas.koc@batman.edu.tr

Geliş Tarihi: 22.07.2019, Kabul Tarihi: 18.02.2020 


\section{Giriş}

İnsan vücudunun en karmaşık organlarından olan insan eli, robotik tutucuların ilham kaynağıdır [1]. Mükemmel bir düzeyde kavrama ve sıkma işlevlerinin yanı sıra gevşetme ve hissetme gibi işlevleri yapan insan eli, bu özellikleriyle robot manipülatörlerinin tasarımında çok iyi bir örnek oluşturmaktadır [2]. İnsan eline benzer mafsallı yapıları takip etmedeki en büyük zorluk, çok fazla serbestlik derecelerine sahip olmasıdır. Üç boyutlu gerçekçi bir insan eli modelinde serbestlik derecesi en az 26 olmaktadır [3]. Tutucu şeklinde kavrama yapma becerisine sahip iki parmağı olan bir mikro tutucu sistemiyle tutma işlemini gerçekleştirme ve iki serbestlik derecesine sahip insan parmağı hareketlerini gerçekleştirecek bir eklem tasarlanmıştır [4,5]. İnsan elinin eklem yapısına uygun bir robotik el tasarımını gerçekleştirirken hata payını yüksek hassasiyette azaltmak için yüksek hız ve doğrulukta taklitçi bir robot el çalışmasında PD kontrolü kullanılmıştır [6,7]. Ayrıca esnek çalışan sensörler ve servo motorla tahrik edilen robot el tasarlanmıştır [8].

Sanayi, imalat ve sağlık endüstrisinde kullanılan robotlar kaynak, taşıma, paketleme, yapıştırma, ameliyat vb. pek çok alanda tercih edilmektedir [9]. İmalat endüstrisindeki robot kullanımıyla birlikte ürün artışı, yüksek verimlilik, kalite artışı, gıda sektöründe sağlıklı ürün elde edilmesi ve insan gücüne olan talebin azalması gibi pek çok avantaj sağlamaktadır [10]. Endüstriyel tutucuların çoğu genellikle iki ya da üç parmaklıdır. Tek tip kavrama gerçekleştirilmekte ve tek tahrikle kontrol edilmektedir. Bu tip sistemlerin kontrolü ve tasarımı kolay iken esnekliği ise yeterli olmamaktadır [11]. Her bir kavrama kolunun ne kadar basınç uygulayacağı ve nerede duracağına karar verebilmesi için farklı hesaplama yöntemlerinin kullanılması gerekmektedir [12]. Bir tutucu kolunun iyi bir şekilde çalışmasını yapabilmesi için tutucu kollarının iş parçasını tanıyabilmesi, bulunduğu noktanın koordinatlarının bilinmesi, hangi yönde parçanın kavranacağını tanımlaması ve iş parçasına göre tutucu kollarının pozisyonlarının bilinmesi gibi özelliklere sahip olması gerekmektedir [13].

Operatörlerin yaptığı görevlerde basit ve tekrarlayıcı seçim ve yer tipi işlemlerin yapılması amacıyla kullanılan kavrama ve taşıma mekanizmaları, insan eliyle kıyaslayan yetenekli aygıtla sağlanmaktadır [14]. Güvenilir, hızlı ve orijinalinden bir şey kaybetmeden serbest düzensiz bir malzemenin taşıma işlemini otomatik olarak yapabilecek şekilde tasarlanan tutucu prototipi endüstriyel bir robot manipülatörüyle çalıştırılacak şekilde entegre edilmektedir [15]. Elektrik ile tahrik edilen silindirin kullanılması pnömatik veya hidrolik ile tahrik edilen silindirlerin kullanımına göre avantajlar elde edilmektedir [16]. Karşılıklı kontörlü yüzleri bulunan iş parçalarını kavrayacak bir endüstriyel robot tutucusu, paralel kollar tarafından tutulan kıskaçlardan ve bağlantının bir ucunda sıkıştırma çenesini taşıyan bir kuplör bağlantısından oluşmaktadır [17]. Esnek flaman ve 3D baskı kullanılarak şekil değişikliğine uğrayan nesneleri kavramak için iki parmaklı, motorlu ve çalışmalara uyum sağlayan bir tutucu, uyumlu parmaklar hareket ettirilmesiyle kavrama hareketini gerçekleştirmektedir [18].

\section{Materyal ve Metot}

Endüstrideki çalışmalarda farklılık gösteren iş, yapılacak parçanın tutulması ve bırakılması hareketleridir. Robotların yaptığı işi ve robotun esas çalışma alanını belirleyen parçası tutucu kol (gripper) ve sistemidir [19, 20]. Her çalışmaya özgü birer tutucu kol bulunmakla birlikte bunların kontrolünde de çeşitli yöntemler bulunmaktadır. Bu yöntemlerin en önemli olanları mekanik hareketler yaptırılarak parçanın tutulması ve bırakılmasıdır. Bu çalışmada silindirik ve dikdörtgenler prizması şeklinde parçaları tutmak için üzerinde $\mathrm{V}$ kanalı bulunan simetrik olarak açılıp kapanan iki tutucu kola sahip bir tutucu tasarımı yapılarak imalatı gerçekleştirilmektedir. Simetrik olan tutucu kolların tahrik edilmesiyle kollar birlikte kapanarak parçayı kavraması tersi yönde ise açılarak parçayı bırakması sağlanmaktadır.

\subsection{Robot tutucu tasarımı ve imalatı}

Robot tutucusunun silindirik ve dikdörtgenler prizması şeklinde parçaları tutmak için Şekil 1'de görüldüğü gibi üzerinde V kanal bulunan, simetrik olarak aç1lıp kapanan iki tutucu kol tasarlanarak imal edilmektedir. Tutucu kollar iki adet vidalı mil vasitasıyla simetrik olarak aç1lı kapanmaktadır. 

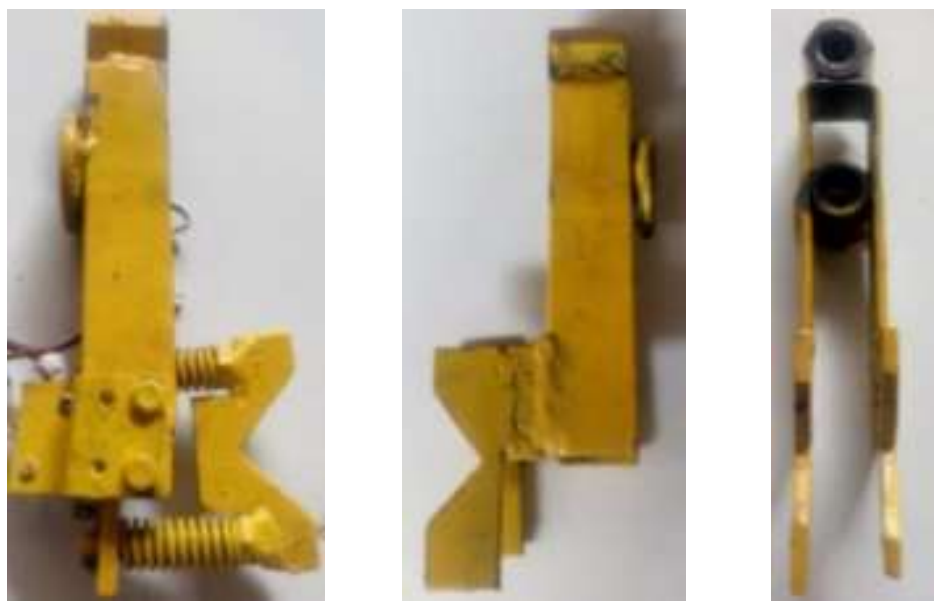

Şekil 1. Tutucu kolları

Şekil 2'de görüldügü gibi tutucu kollar iki adet trapez vidalı miller vasıtasıyla simetrik olarak açılıp kapanmaktadır. Orta kısmından tutucu gövdesine yataklanan vidalı millerin bir tarafinda sağ helis, diğer tarafında ise sol helis trapez vidalar bulunmaktadır.

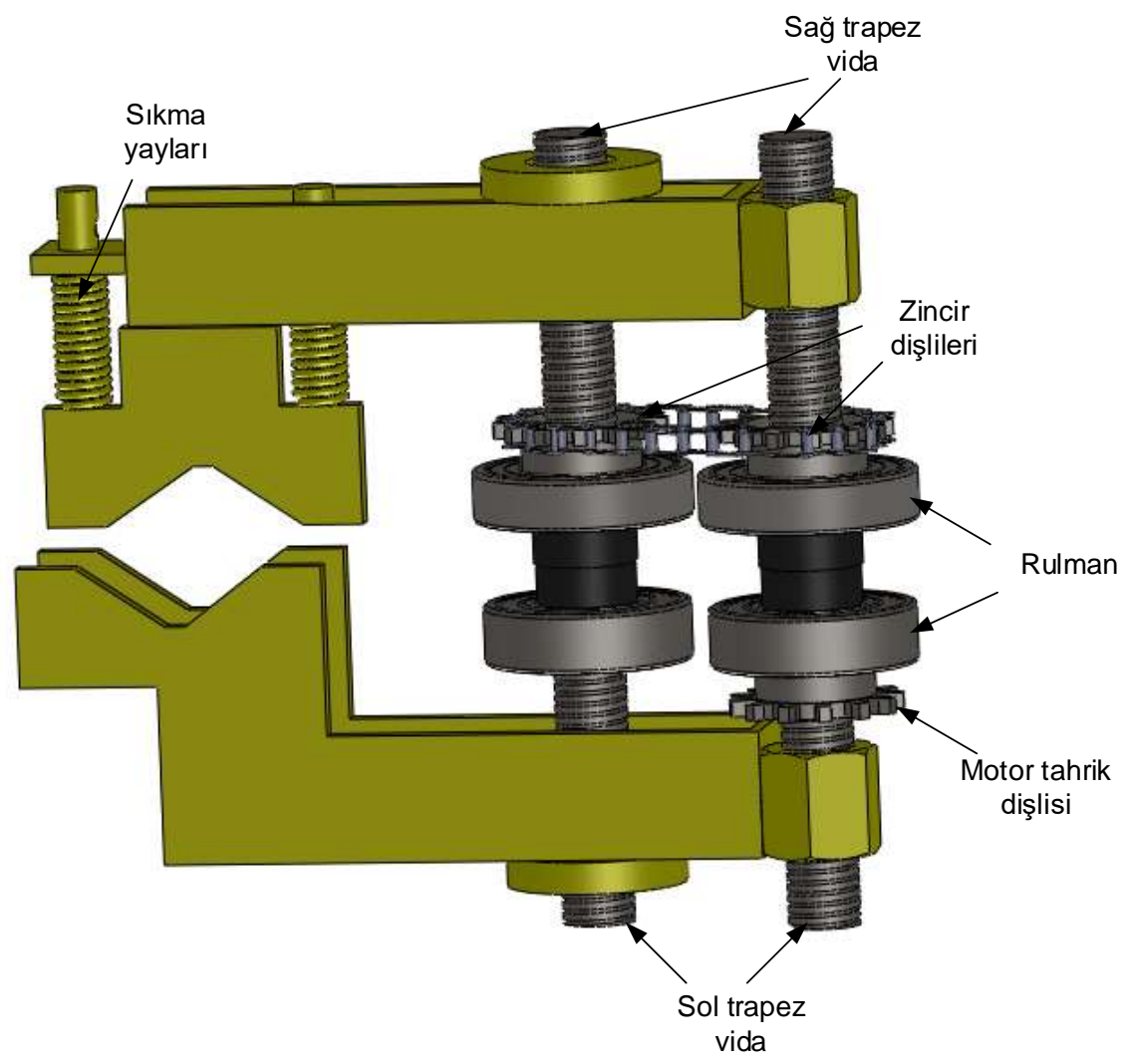

Şekil 2. Tutucu kollarının bağlantı tasarımı

Miller, Şekil 3'de görüldüğü gibi üzerlerine montaj edilen zincir ve dişli sistemi ile her ikisi birlikte dönmektedir. Bir tutucu kol üzerine iki adet somun montaj edilerek simetrik olarak yerleştirilmektedir. Bu sayede miller saat yönüne çevrildiği zaman tutucu çene kapanmakta, saat yönünün tersi istikametinde çevrildiğinde açılmaktadır. 


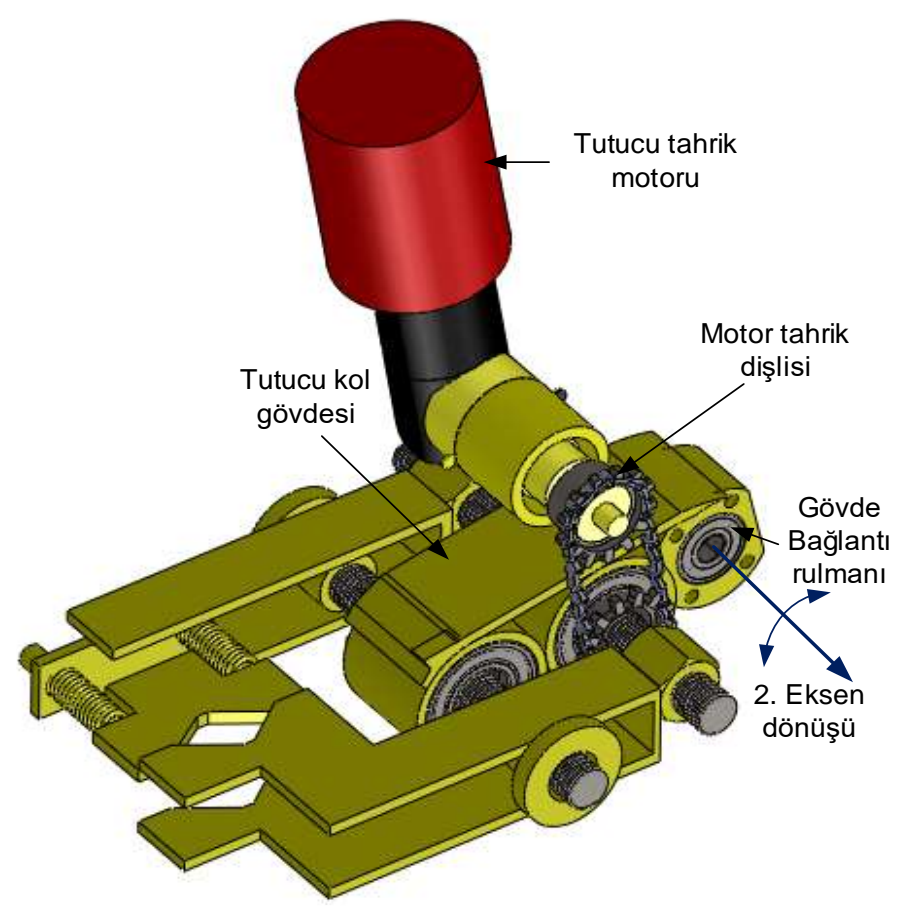

Şekil 3. Tutucu tahrik sistemi tasarımı

Tutucu kolları açıp kapatmak için redüktörlü dik açılı bir elektrik motoru kullanılarak Şekil 4'de görüldüğ̈̈ gibi tutucu gövde üzerine dik olarak montaj edilerek motor miline takılan bir zincir dişli ile vidalı millere hareket verilmektedir.
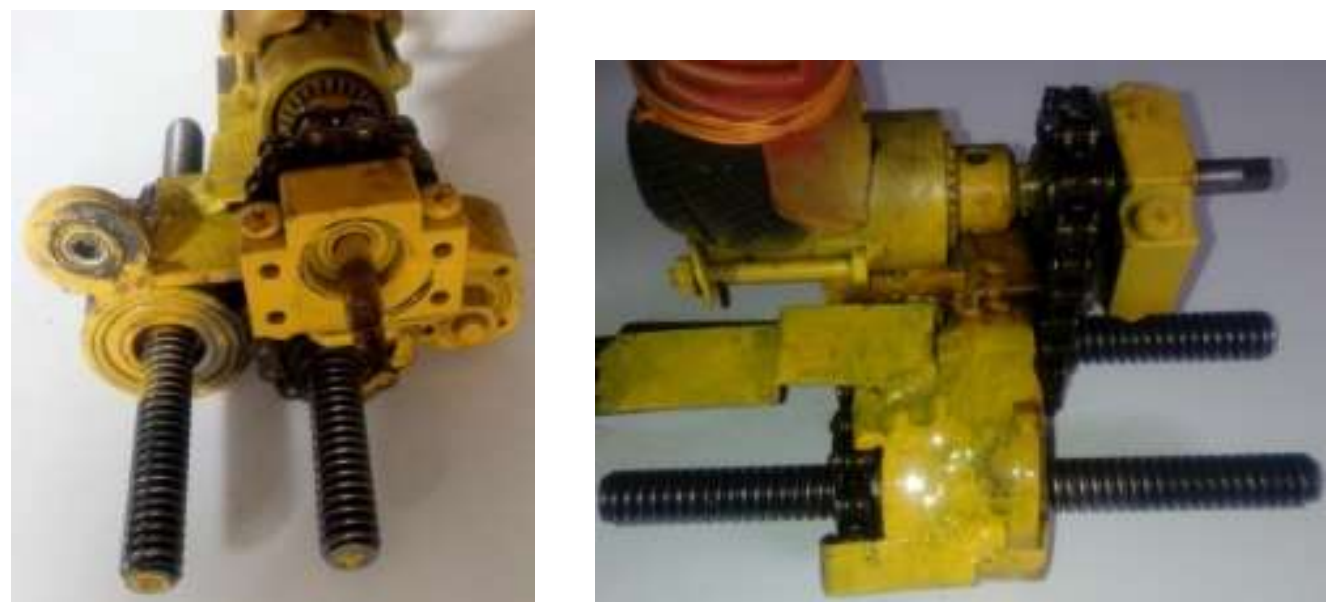

Şekil 4. Trapez vidaların rulmanlarla montajı

Parçaları tutma sırasında tutucu kolun uyguladığı sıkma kuvvetini kontrol altına almak için sağ tutucu kolda bulunan V blok birbirine paralel iki silindirik mil ile kola dik olarak yataklanarak aralarına baskı yayları yerleştirilmektedir. Şekil 5'de görüldüğü gibi çenelere uygulanan kuvveti ayarlamak içinde tutucu kol ile hareketli çene arasına mikro anahtar yerleştirilerek tutucu çenenin açlıp kapanma miktarı kontrol altına alınmaktadır. Hazırlanan bir elektrik devre bağlantısıyla tutucu kol motoruna akım verildiğinde $\mathrm{V}$ çeneli tutucu kollar kapanarak parçaya basma kuvveti uyguladıktan sonra durmaktadır. Tutucu kolları açmak için, tutucu kol tahrik motoru ters yönde döndürülerek açılan tutucu kollar mikro anahtara temas ederek motorun durması sağlanmaktadır. Bu sayede silindirik veya prizmatik parçalar robot tutucu kolu çeneleri arasına konsantrik olarak tutulmaktadır. 

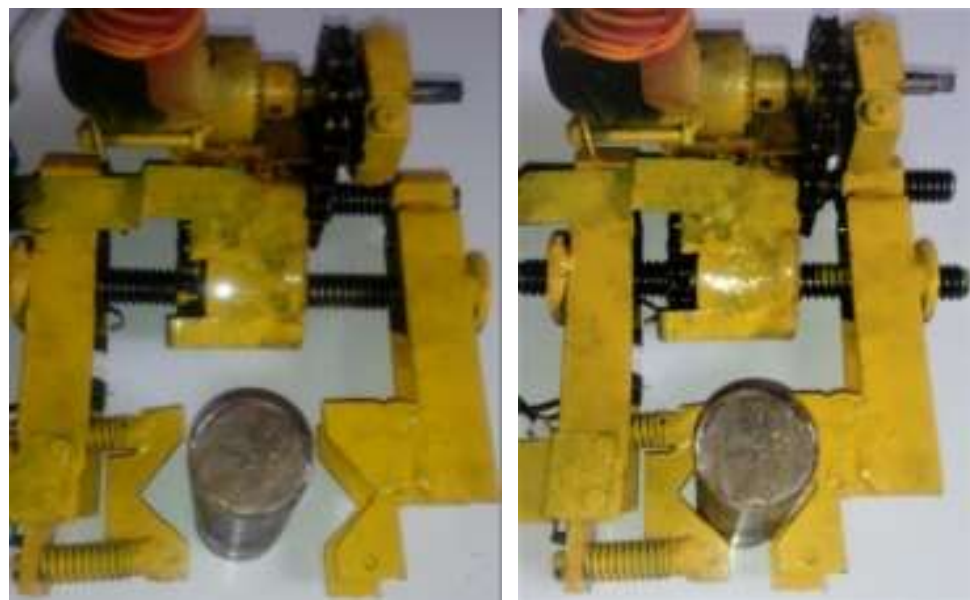

Şekil 5. Tutucunun parçayı kavraması ve bırakması

\subsection{Robot tutucusu 1. ve 2. eksen hareketleri}

Robot manipülatörleri incelendiğinde robotların hareketlerini yapmak için ilk 3 eksen kullanılırken diğer eksenler ise robot uç işlevcisinin konumu ve yöneliminde kullanılmaktadır. Kinematik denklemler incelendiğinde robotun esas hareketini yapan ilk üç eksenin yanında döndürme merkezleri aynı olan euler bilekliği veya eklem kaçıklığı olan bilekler kullanılarak uç işlevcisinin döndürme denklemleri oluşturulmaktadır. Bu çalışmada tasarımı yapılan gripper ucuna takılacak olan robot kolun uç işlevcisi görevinin yanı sıra hareketini sağlayan ilk üç eksenden sonra 4. ve 5. eksen görevini görmektedir. Gripper üzerinde tasarlanan yapıyla sadece kavrama görevi değil aynı zamanda 2 eksen görevini de yerine getirmektedir.

Belirli bir pozisyondaki parçaları tutabilmek için robot tutucusunun tahrik sistemleri tarafindan 1. ve 2. eksenlerde kontrollü olarak dönmesi sağlanmaktadır. Şekil 7'de görüldüğü gibi 2. eksen hareketi için vidalı millere paralel olarak montaj edilen gövde bağlantı rulmanlarını hareket ettirmesi için step motor tahrikli rulmanlı vidalı milli aktüatör kullanılmaktadır. Bu aktüatörde rulmanlı somun step motor miline tespit edilen borunun uç kısmına montaj edilmektedir.

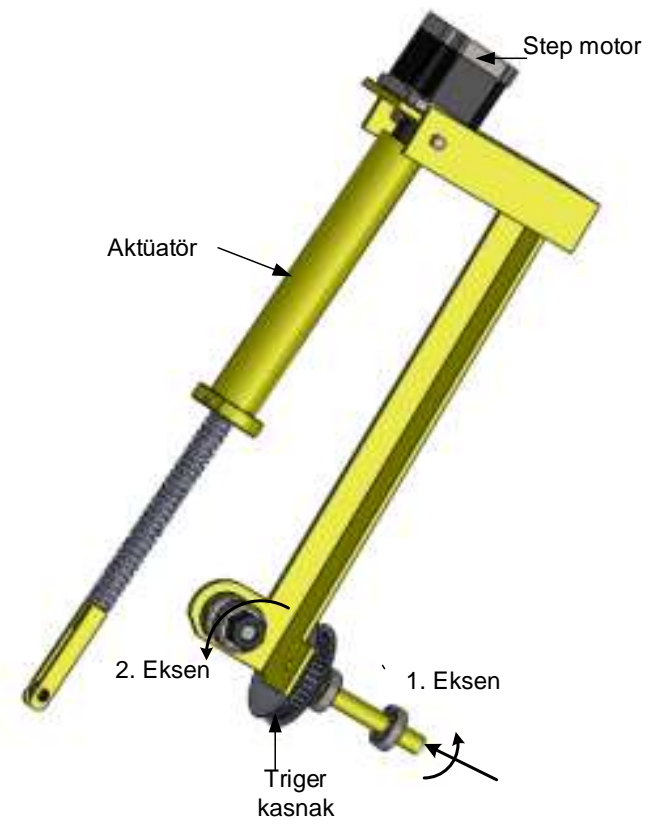

Şekil 7. Tutucu taşıyıcı gövdesi tasarımı

Vidalı mili tutucu gövdeye rulmanlarla Şekil 7'de görüldügü gibi montaj edilerek ucunda rulman montaj edilen borunun step motor tarafindan döndürülmesi ile tutucu gövde bağlantı rulmanları 2. eksen doğrultusunda 90 derece dönmesi sağlanmaktadır. Robot tutucu aksamın robot kol ucuna 
montajının yapılabilmesi için robot kolun uç kısmına birbirine paralel iki rulman kullanılarak tutucunun 1. eksen hareketini yapan mil rulmanlara yerleştirilerek eksen etrafinda dönmesi sağlanmaktadır. 1 . eksen tutucu gövde bağlantı mili robot kolu uçuna montaj edilen bir step motor triger bağlantısı sistemi ile kontrollü olarak 180 derece dönmesi sağlanmaktadır. Bu sayede robot tutucusu herhangi bir pozisyondaki parçaları tutarak 2 eksende hareket ettirerek istenilen pozisyonda burakılması sağlanmaktadır.

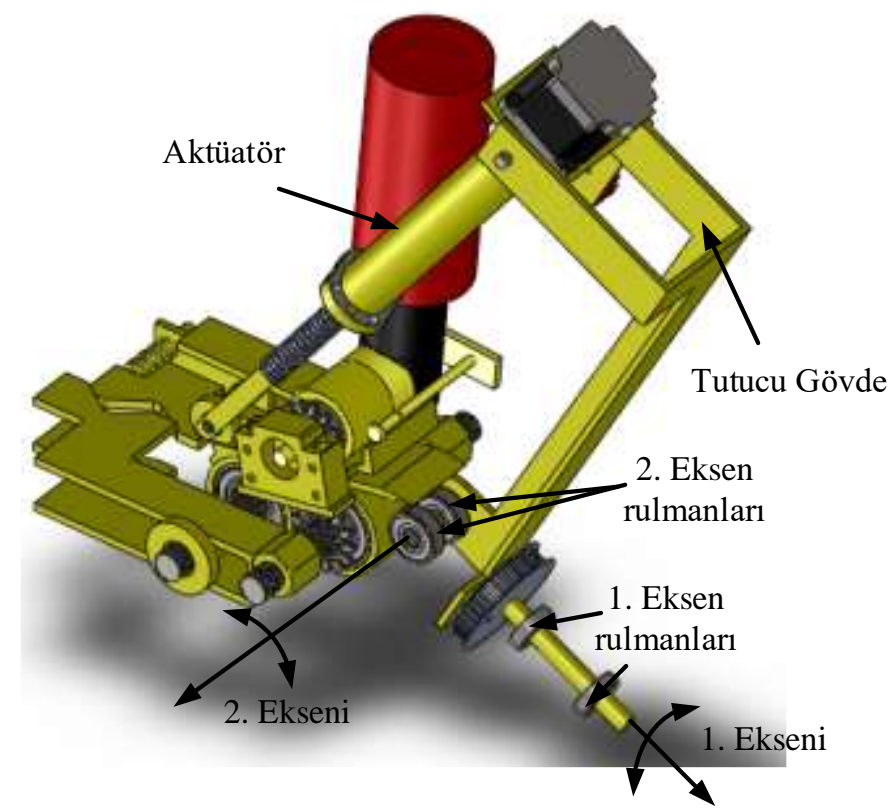

Şekil 7. Tutucu kolların 1. ve 2. dönüş eksenleri

Robot tutucusunun kavrama kollarının tasarlanması, tahrik motorunun gövde üzerine yerleştirilmesi, tutucu kollarının açılıp kapanmasını kontrol altına alınması ve tutucunun iki ekseninin montaj1 yapılarak Şekil 8'de görüldüğü gibi bir robot kol ucuna montaj1 yapılarak çalıştırılmaktadır.

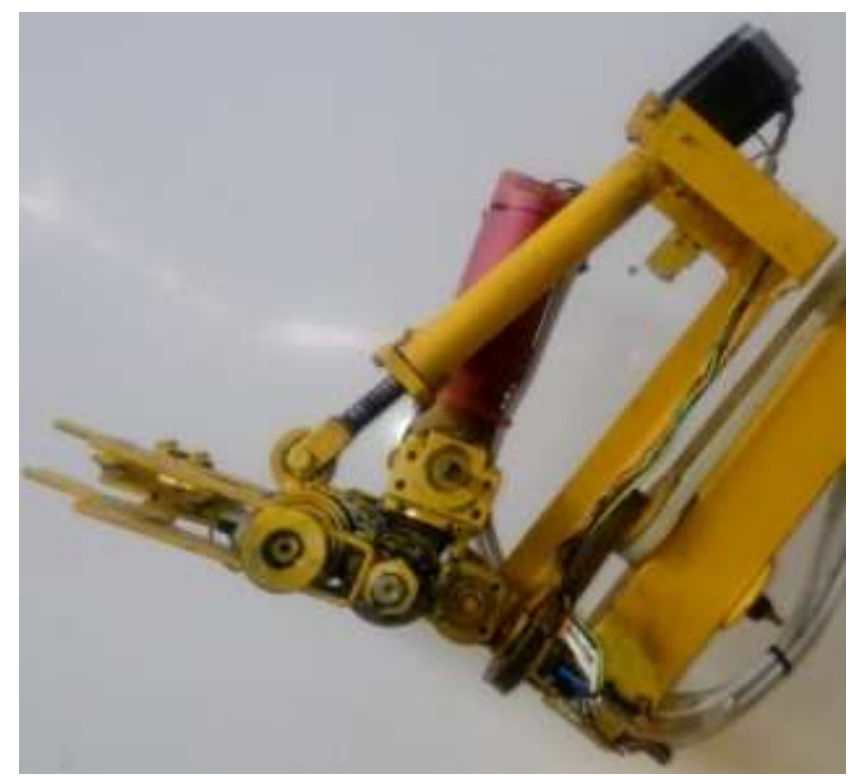

Şekil 8. Robot tutucusunun robot kola montaj1

\subsection{Tutucunun kontrolü}

Motoru sağa ve sola çevirmek için 4 adet yön girişi bulunan ve bu girişleri bağlamak içinde 2 açık ve 2 kapalı kontağı bulunan $24 \mathrm{~V}$ AC kontaktörü kullanılmaktadır. Kontaktör açık iken motoru sağa çevirmek 
için 1 nolu 24 V DC kontaktörü aktif duruma getirilerek normalde açık ve kapalı kontaklar üzerinden 1 ve 2 ile 3 ve 4 uçları kısa devre edilmektedir. Motoru sola çevirmek için 1 nolu kontaktörün enerjisi kesilerek kontaktör kapalı duruma getirilerek 1 ve 3 ile 2 ve 4 nolu uçlar kısa devre edilmektedir.

Robot tutucu kollarını hareket ettiren vidalı milleri çevirmede $220 \mathrm{~V}$ AC motorunun, tutucu kolları açma ve kapamada sınır anahtarlarının ve motorun çalıştırılması için Şekil 9'da görüldügü gibi 1, 2, 3 ve 4 nolu 4 adet 24 V DC kontaktörünün kontrolünü sağlamak amacıyla Mach3 kartı Output 2, 3, 4 ve 6 numaralı çıkışları kullanılmaktadır. Bu çıkışların kullanılması için Mach3 programında kullanılan kartın tanımlanması yapılarak output pinlerinin aktif edilerek çalışmaya hazır duruma getirilmektedir.

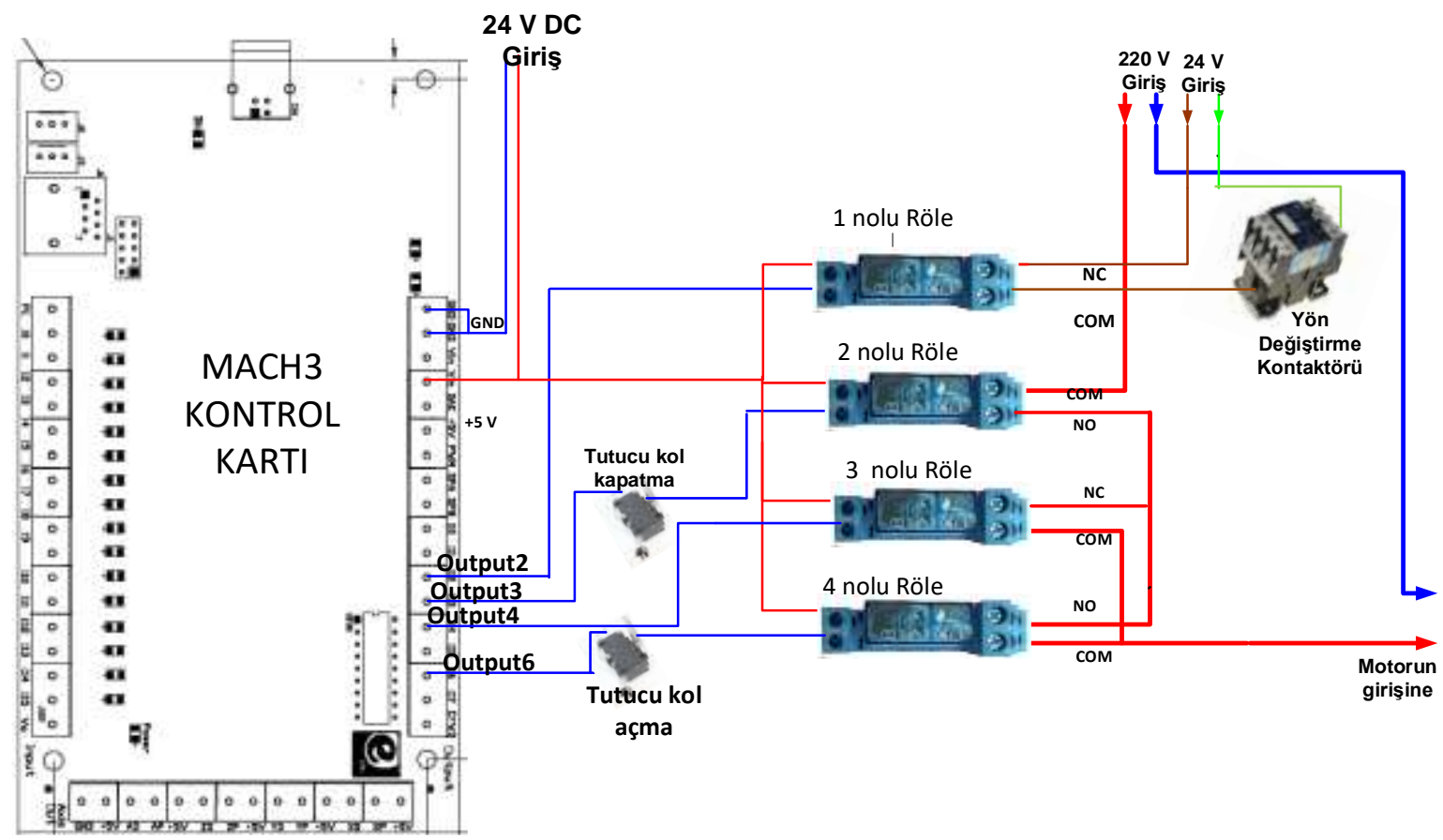

Şekil 9. Tutucu kol motorunun röle ve kart bağlantısı

\section{Bulgular ve Tartışma}

$\mathrm{Bu}$ çalışmada kullanılan mekanik robot tutucusunu tahrik eden motorun mevcut piyasada bulunan matkap motoru olduğundan kontrol edilmesinde zorluklar oluşturmaktadır. Pnömatik, hidrolik ve mekanik tutucu tahriklerinde kullanılan kontrol mekanizması belli çalışma sınırlarında açma ve kapama hareketleri yapmaktadır. Bu tür sistemlerde kullanılan motorların ilerlemesi ve nerede duracağ belli olmasına karşın bu çalışmada kullanılan motorun çalışmalarını sınırlandırmak için mekanik sınır anahtarlarından ve yaydan yararlanılmaktadır. Sistemde kullanılan 3 adet sinır anahtarı ile tutucunun ne kadar açılacağını, ne kadar kapanacağını ve parçayı kavrama esnasında ne kadar sıkmadan sonra motorun enerjisini keseceğini belirlemek için kullanılmaktadır. Sınır anahtarlarının kullanılmasıyla sistem kontrol edilirken bu anahtarlamanın otomatik olarak yapılması için de kontrol kartının alt programları olan makrolardan yararlanılmaktadır. Kullanılan makroların kodları çalışmaya özgün olarak yazılarak sistemin açılması ve kapanması işlemi gerçekleştirilmektedir. Makroların çalıştırılması ve isimlendirilmesinde $\mathrm{m}, 2$ ve 5 karakterlerinden oluşturulmasına dikkat edilmektedir. Mach3 programında hazırlanan makroların $\mathrm{m}$ harfiyle başlaması, sistemde makroların çalıştırılması ve bu makroların ekrana yazdırılmasında kolaylık sağlanması için sadece 2 ve 5 rakamlarından oluşan makro isimlerinden yararlanmaktadır. Böylece makroların robot yörüngesinde kullanılması ve robotun işlemi otomatik olarak yapmasının yanı sıra bu makrolar bir sistem yardımıyla Mach3 ekranına yazdırılarak kullanılmaktadır.

Şekil 10'da görülen m222 makrosu ile robot tutucu kolların kapatılması ve m555 makrosu ile açılması sağlanmaktadır. Tutucu kol parçaya yaklaştıktan 0.5 saniye sonra tutucu kolları kapatmakta 3 saniye bekledikten sonra aktif olan çıkışları açarak 0.5 saniye sonra çalışmasına devam etmektedir. Aynı şekilde robot durduktan 0.5 saniye sonra tutucu kolları açmakta 3 saniye bekledikten sonra aktif olan 
çıkışları pasif yaparak tutucu kol motorunun enerjisi keserek 0.5 saniye sonra çalışmasına devam etmektedir.

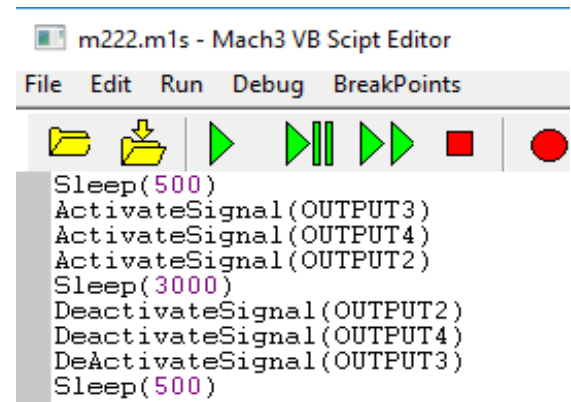

m555.m1s - Mach3 VB Scipt Editor

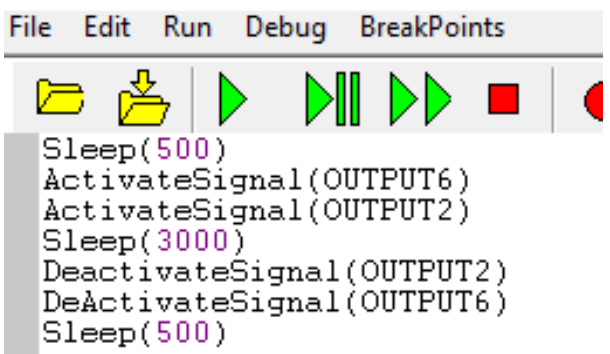

Şekil 10. $\mathrm{m} 222$ ve m555 makroları

Şekil 11'deki m5 makrosu, robot hareketlerine ait eksen değerlerini metin dosyasına yazdırmaktadır. Mach3 programında X ekseni için 0, Y ekseni için 1, Z ekseni için 2, A ekseni için 3, $\mathrm{B}$ ekseni için 4 ve C ekseni için 5 kullanılarak GetDRO komutu ile her eksenin aktif olan son eksen değerleri alınarak değişkene tanımlanmaktadır. Alınan eksen değerleri satııının başına G1 doğrusal hareket kodu ve satır sonuna da f ilerleme hızı eklenerek metin dosyasına sırasıyla yazdırılarak kapatılmaktadır. Satır başına yazdırılan $G$ kodu ve sonuna yazılan f ilerleme hızı değeri robotun yörüngesi için gerekli olan kod oluşturulduktan sonra robota yüklendiğinde robot burada kullanılan $G$ koduna göre hareketini yapmaktadır.

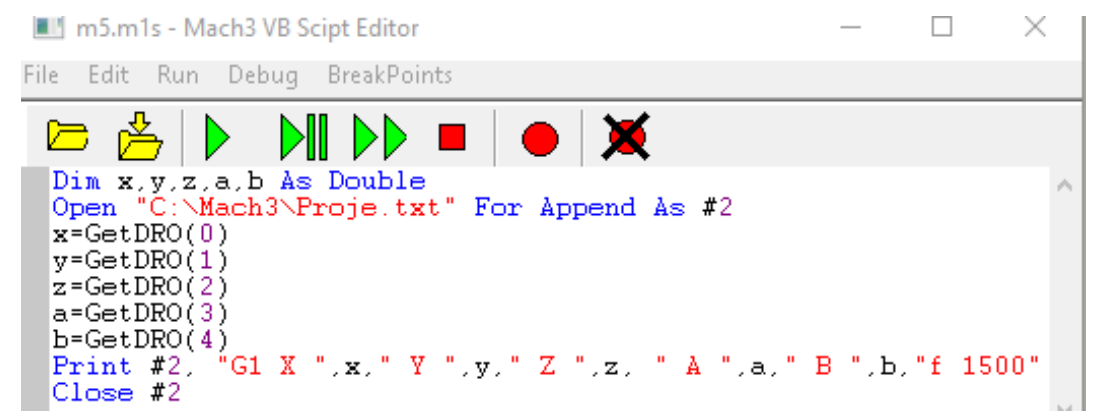

Şekil 11. m5 makrosu

Şekil 12'de görülen m22 makrosu robot kolun yörüngesinin belirlenmesi amaciyla gitmesi gereken noktaların eksen değerlerini kaydetmek ve tutucunun parçayı alma noktasına geldiğinde kavrama hareketini yapması için m222 makrosunu hareket yörüngesine yazdırmaktadır. M55 makrosu da tutucunun parçayı bırakma noktasına geldiğinde kolların açılarak parçayı bırakması hareketi için m555 makrosunu hareket yörüngesine yazdırmaktadır. Robot hareket yörüngesi belirlendikten ve yörünge boyunca gidecek noktalar ile bu noktaların eksen değerlerine G1 ve f değerleri eklendikten sonra oluşturulan dosya programa yüklenerek çalıştırıldığında parçanın alma pozisyonuna geldiğinde m222 makrosuyla parçayı alarak m555 makrosuyla da parçayı bırakarak görevini yapmaktadır.

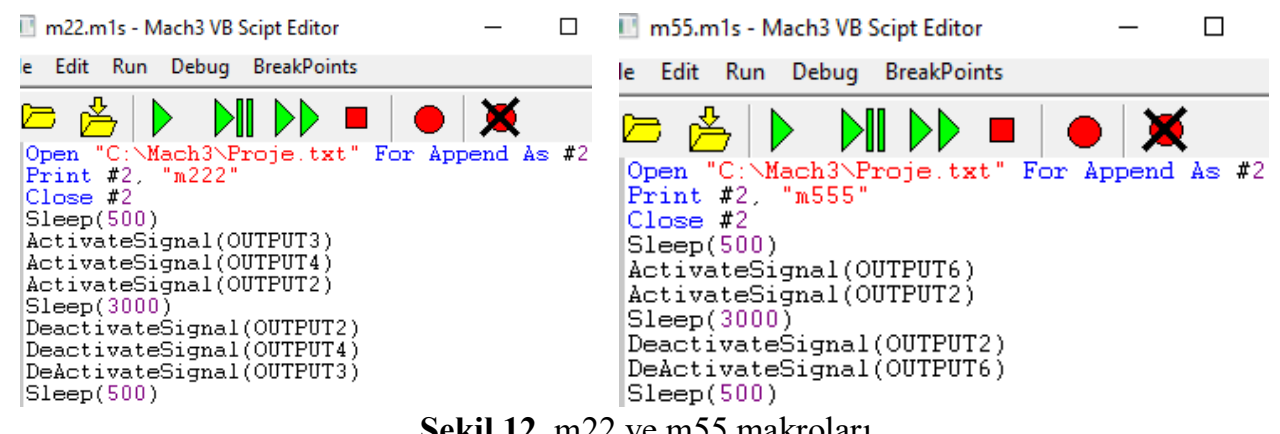

Şekil 12. m22 ve m55 makrolar1 
Robotların hareketlerini oluşturan eksenlerin tasarlanması ve bunların kontrollerinin yapılması robot teknolojisi için ne kadar önemliyse robotların yaptıkları işleri belirleyen robot işlevcisi olan tutucularda o kadar önemlidir. Robotun hareketlerindeki farklılıklardan hareketle robotların sınıflandırılması yapıldığı gibi tutucuların da çalışma şekilleri, parçayı kavrama ve tahrik sistemi de robot tutucularının sınıflandırma parametrelerini oluşturmaktadır. Çalışma alanlarına göre oluşturulan robotların tutucuları, hidrolik, pnömatik ve elektrikle tahrik edilen sistemleri kullanarak hareket etmektedir. Elektrikle tahrik edilen sistemlerde genellikle step veya servo motorlar kullanılmaktadır. Robot tutucularının kavrama çeneleri genellikle 2 veya 3 kolla yapılmaktadır. Bu çalışmada tasarlanan robot tutucusu mekanik olarak kavrama işlemi yapmaktadır. İki tarafına yerleştirilen sağ ve sol trapez vidalar simetrik olarak açılıp kapanmasıyla parça düzgün bir şekilde kavranmaktadır. Step motor yerine dik açılı bir elektrik motoru kullanılarak parçanın tutulmasıyla birlikte bırakılma işleminde dişlilerden kaynaklı tutucuların açılmasında tıkanıklık yaşanmaması ve sistemde daha fazla yük taşıma sağlanması için kullanılmaktadır. Step ve servo motor ile tasarlanan sistemlerde dişlilerin birlikte çalışması esnasında dişlilerin pozisyonlarından kaynaklı açılması için gerekli olan güç motor tarafindan sağlanamadığında sistemin otomatik ve kontrollü olarak çalışmasında problemler oluşturmaktadır. Motorun sıkma miktarını ayarlamak ve sıkma esnasında kullanılan baskının bir kısmını karşılamak ve açılmasında dişlilerden kaynaklı sıkışmaları engellemek için bir kolun arkasına iki mil yerleştirilerek bu millerin üzerine montaj edilen yaylar kullanılmaktadır. Tutucu kolların açılıp kapanmasını kontrol altına almak için sınır anahtarları yerleştirilerek açılma ve kapanma miktarı, motorun sıkma miktarı ve boşta çalışma esnasında kapanması durumunda sıkışmaları engellemek gibi hataların oluşmasının önüne geçilmektedir.

$\mathrm{Bu}$ çalışmada kullanılan mekanik tutucu içine yerleştirilen $25-75 \mathrm{~mm}$ çapında silindirik veya dikdörtgen parçaların alınması, taşınması ve bırakılması işlemlerinde çalışmaktadır. Daha küçük çaptaki veya daha büyük çaptaki parçaları almada hataların önüne geçmek için sistemi sınırlandırmak amacıyla sınır anahtarları kullanılmaktadır. Sistemde vidalı miller kullanıldığından millerin sıkmasında vida dişlerinin somunlar üzerinde oluşturduğu kuvvetlerinin etkisiyle açma esnasında sıkmak için gerekli olan kuvvetten daha fazla bir kuvvete ihtiyaç duyulmaktadır. Tutucuda step motor kullanıldığında parçayı kavraması sırasında bir sorun ile karşılaşmamasına karşın açma esnasında aynı torktaki step motorun uyguladığı kuvvet yetersiz kalmaktadır. Bu yetersizliği ortadan kaldırmak için iki tutucu koldan birine sıkma kuvvetinin bir kısmını karşılamak için iki adet yay kullanılmaktadır. Bu yaylar sistem kapama esnasında sıkma kuvvetinin bir kısmını geri teperek hataların önüne geçerken tutucunun taşıdığı parçanın ağırlığında olumsuz etki yarattığı saptanmaktadır. Yayların oluşturduğu olumsuz etki ise tutucu 5 kg üzeri ağırlıkların taşınmasında yayın esnemesinden dolayı parçayı dik tutmakta zorlanmaktadır. Tüm özellikler dikkate alındığında sistem $25-75 \mathrm{~mm}$ çapında ve $0-5 \mathrm{~kg}$ ağırlığında bulunan malzemeleri taşıma kapasitesine sahip olduğu saptanmaktadır. Sistemi kontrol etmek ve robotun hareket yörüngesinde tutucunun kullanımını sağlamak için oluşturulan makrolar bir robot için genelleştirilerek robotun beş eksende kontrollü bir şekilde kullanılması sağlanabilmektedir. Bu sistemin çalıştırılmasında ve robotun kontrol edilmesinde kullanılan makrolar daha önce CNC sistemlerinde kullanılan G kodlarından esinlenerek hareket oluşturulmaktadır. Mach3 ile kontrol edilmesinde maliyetin düşürülmesine karşın haberleşme portallarının oluşturduğu sıkıntılarda bu sistemin kullanılmasında engel oluşturmaktadır.

\section{Sonuç ve Öneriler}

Bu tutucu endüstride parçaları güvenli bir şekilde bantlar üzerinden alıp başka çalışmalar için kullanılan bant sistemlerine yerleştirme işlemlerinde kullanılabildiği gibi parçaların bir yerden alınarak bir kutu ya da bir parça üzerine dizilmesi işlemlerinde de kullanılabilmektedir. Elektrik motorunun oluşturduğu torktan yararlanarak daha ağır parçalar taşınmaktadır. Tutucu mekanizma üzerinde bulunan birbirine dik iki eksen kullanılmasıyla 3 eksen hareket edebilen bir robot sisteminde montaj edilerek çalıştırabilecek şekilde tasarlanmaktadır. Tasarlanan tutucu montajı yapılarak bir robot kol üzerinde denenerek parçaların alınması ve bırakılması işlemlerini başarılı bir şekilde gerçekleştirilmiştir. 2 eksenin tutucu sistemi üzerinde bulunmasiyla uzayda 3 eksende hareket edebilen robotlarda montaj edilerek 3 eksen olarak tasarlanan robot kolun 5 eksen olarak çalışmasını sağlamaktadır. Böylece 3 ana eksende hareket sağlayan bir robotun uçuna takıldığında tutucu üzerinde bulunan kendi eksenleri yardımıyla 5 eksende çalışarak iş yapabilecek kabiliyet kazandırılmaktadır. 
Günümüz endüstri teknolojisinde çalsşmaların büyük bir kısmını robotlar oluşturduğundan dolayı bu alanla ilgili yapılan çalışmalar da dikkat çekmektedir. Bu alanda hem robotların çalışma fonksiyonları ve kontrol sistemlerinin özellikleri hem de çalışma ortamı içerisinde parçayı işlemek veya taşımak için gerekli olan tutucuların özellikleri önemsenmektedir. Bu çalışmada tasarlanarak imal edilen tutucunun kavrama kabiliyetinin geliştirilmesi, tutucu çenelerinin silindirik ve prizmatik parçalarının yanı sıra diğer şekillere sahip nesnelerin taşınmasında kullanılmak üzere tasarımının geliştirilmesi sağlanmalıdır. Kullanılan motorun kontrol sisteminin bulunmaması ve çalışma sınırlarının belirlenmesinde kullanılan sınır anahtarlarının oluşturduğu ekstra maliyetinin azaltılması için kontrol edilebilen motorların sistemde çalışmasını sağlayacak tasarımların geliştirilmesine olanak sağlanmalıdır.

\section{Teșekkür}

Bu tutucu tasarım ve montajında proje desteğini sağlayan Harran Üniversitesi Bilimsel Araştırmalar Koordinatörlüğü (HÜBAK)'ne teşekkür ederim.

\section{Yazarların Katkısı}

Tutucunun tasarımı ve imalatında yazarlar eşit oranda, makalenin yazımında Savaş KOÇ (\%75) oranında katkı sunmuştur.

\section{Çıkar Çatışması Beyanı}

Yazarlar arasında herhangi bir çıkar çatışması bulunmamaktadır.

\section{Araştırma ve Yayın Etiği Beyanı}

Yapılan çalışmada araştırma ve yayın etiğine uyulmuştur.

\section{Kaynaklar}

[1] Karaçizmeli C., Gökçe Ç., Dilek T. 2014. Robotik El Projesi. 22nd Signal Processing and Communications Applications Conference (SIU), Trabzon, pp.473-476.

[2] Özkan S.S., Karayel D., Atalı G., Gökbayrak İ. 2007. Esnek Algılayıcı Kontrollü Robot El Tasarımı ve Gerçeklenmesi. Akademik Platform Mühendislik ve Fen Bilimleri Dergisi, 5 (3): 3540.

[3] Bray M., Koller-Meier E., Müller P., Schraudolph N.N., Van Gool L. 2005. Stochastic Optimization for High-Dimensional Tracking in Dense Range Maps. IEE Proceedings-Vision, Image and Signal Processing, 152 (4): 501-512.

[4] Lan C.C., Lin C.M., Fan C.H. 2011. A Self-Sensing Microgripper Module with Wide Handling Ranges. IEEE/ASME Transactions on Mechatronics, 16 (1): 141-150.

[5] Ryew S., Choi H. 2001. Double Active Universal Joint (Dauj): Robotic Joint Mechanism for Human-Like Motions. IEEE Transactions on Robotics and Automation, 17 (3): 290-300.

[6] Xu Z., Todorov E. 2016. Design of a Highly Biomimetic Anthropomorphic Robotic Hand Towards Artificial Limb Regeneration. 2016 IEEE International Conference on Robotics and Automation (ICRA). IEEE, Stockholm, pp.3485-3492.

[7] Hoshino K. 2007. Copycat Hand-Robot Hand Generating Imitative Behaviour at High Speed and with High Accuracy. Humanoid Robots: New Developments, IntechOpen, 582s. Vienna.

[8] Hande J.Y., Malusare N., SubodhSawarbandhe H.D. 2015. Design for Robotic Hand Using Flexsensor. International Journal of Advanced Research in Electronics and Communication Engineering (IJARECE), 4 (12): 2846-2850.

[9] Kayışlı K., Uğur M. 2017. Fuzzy Logic and PID Control of a 3 DOF Robotic Arm. Gazi Üniversitesi Fen Bilimleri Dergisi Part C: Tasarım ve Teknoloji, 5 (4): 223-233.

[10] Gray J.O., Al Janabi T.H. 1976. Toward the Numerical Design of Nonlinear Feedback Systems by Zakian's Method of Inequalities. IFAC Proceedings, 9 (3): 327-334. 
[11] Gökbayrak İ., Özkan S.S., Karayel D., Atali G. 2016. Esnek Algılayıcı Kontrollü Robot El Tasarımı ve Gerçeklenmesi Üzerine Bir Çalışma. 4th International Symposium on Innovative Technologies in Engineering and Science (ISITES2016), Antalya, pp.954-960.

[12] Brown E., Rodenberg N., Amend J., Mozeika A., Steltz E., Zakin M.R., Lipson H., Jaeger H.M. 2010. Universal Robotic Gripper Based on the Jamming of Granular Material. Proceedings of the National Academy of Sciences, 107 (44): 18809-18814.

[13] Snyder W.E., Clair J.S. 1978. Conductive Elastomers as a Sensor for Industrial Parts Handling Equipment. IEEE Transactions on Instrumentation and Measurement, 27 (1): 94-99.

[14] Chua P.Y., Ilschner T., Caldwell D.G. 2003. Robotic Manipulation of Food Products-a Review. Industrial Robot: An International Journal, 30 (4): 345-354.

[15] Kolluru R., Valavanis K.P. Hebert T.M. 1998. Modeling, Analysis, and Performance Evaluation of a Robotic Gripper System for Limp Material Handling. IEEE Transactions on Systems, Man, and Cybernetics, Part B (Cybernetics), 28 (3): 480-486.

[16] Tavakoli M., Zakerzadeh M.R., Vossoughi G.R., Bagheri S. 2005. A Hybrid Pole Climbing and Manipulating Robot with Minimum Dofs for Construction and Service Applications. Industrial Robot: An International Journal, 32 (2): 171-178.

[17] Brockmann K.H., Molder K.P., Wauer G. 1983. Industrial Robot Having a Gripping Device. U.S. Patent No: 4,368,913.

[18] Liu C.H., Chen T.L., Chiu C.H., Hsu M.C., Chen Y., Pai T.Y., Peng W.G., Chiang Y.P. 2018. Optimal Design of a Soft Robotic Gripper for Grasping Unknown Objects. Soft Robotics, 5 (4): 452-465.

[19] Özçelik B., Erzincanlı F., Kandemir İ. 2001. Kumaşların Kaldırılmasında Kullanılan Robot Ellerin Karşılaştırılması ve Sistemin Tanıtımı. Makina Tasarım ve İmalat Dergisi, 4 (1): 11-19.

[20] Pham D.T., Yeo S.H. 1988. A knowledge-based System for Robot Gripper Selection: Criteria for Choosing Grippers and Surfaces for Gripping. International Journal of Machine Tools and Manufacture, 28 (4): 301-313. 